\title{
Near-ground Measurement and Modeling for Archaeological Park of Pisac in Cusco for LoRa Technology
}

\author{
Yhon D. Lezama ${ }^{1}$, Jinmi Lezama ${ }^{2}$, Jorge Arizaca-Cusicuna ${ }^{3}$ \\ Universidad Nacional San Antonio Abad del Cusco - UNSAAC ${ }^{1,3}$ \\ Universidad Nacional Tecnológica de Lima Sur - UNTELS ${ }^{2}$
}

\begin{abstract}
This research work presents the details of a nearground received power measurement and modeling based on it, inside the archaeological park of Pisac in the city of Cusco. The measurements were performed at a working frequency of $920 \mathrm{MHz}$ in the industrial, scientific, and medical (ISM) band, using transceiver devices with LoRa technology. The power of the received signal is obtained while the transmitter moves at a constant speed of $0.4 \mathrm{~m} / \mathrm{s}$, to characterize the fading that occurred within this archaeological park, making appropriate use of the moving average filter separates the fading to large and small scale, then on the filtered signal is used the algorithm of linear regression, to obtain a model that characterizes the exponent of propagation loss and the shading factor. In addition, the small-scale fading is characterized according to its probability distribution, the statistical parameters of the distributions are obtained based on the small-scale measurements. We also measured variations of receiving antenna height, ranging from $20 \mathrm{~cm}, 50 \mathrm{~cm}, 80 \mathrm{~cm}$, and $120 \mathrm{~cm}$ above the ground, finding that the height has a strong influence on the propagation loss exponent, while the shadow variation shows a smaller variation. The model obtained is validated by the coefficient of determination and the root mean square error (RMSE) value.
\end{abstract}

Keywords-Archaeological park; LoRa; propagation model; statistics; near-ground

\section{INTRODUCTION}

Wireless Sensor network (WSN) applications are constantly increasing, some of them for smart cities, smart buildings, smart parks, smart farms, and recently some application in smart tourism, this is principally for the care of archaeological attractions and monitoring of tourist behavior. Cusco city has different archaeological places. Where it is important to use the technological tools to monitor the archaeological sites to conservation purposes. Internet of things applications are based in 5 layers [1]; perception, transport, processing, applications and business layer. Where perception layer is also known as data acquisition, and transport layer is based in the transfers of sensor data from perception layer to processing layer, in this layer different wireless technologies are used such as; WiFi, Bluetooth, Sigfox, LoRa and Cellular technology. In transport layer, Wireless technology choice is important,because it is necessary to consider; data transmission rate, bandwidth, frequency band (commercial or ISM (Industrial, Scientific or medical)), energy consumption and propagation channel. Therefore, propagation model is an essential tool for WSN planning and deployment [2]. Because, propagation model describes the radio channel characteristics for different environment such as forest, urban and indoor locations. This model will allow the use of location algorithms based on RSS within an archaeological park environment in the city of Cusco or other parks with similar morphology environments. As in [3], where they work in the UHF band at $433 \mathrm{MHZ}$ using LoRa technology, within forestry scenarios described as a clear forest and a rubber plantation. Observing the attenuation of these forest scenarios versus a LOS scenario by obtaining the RSS value, also the variation of SF (Spreading Factor) and BW (BandWidth), to observe its impact on the LoRa signal, concluding that the propagation loss in a forest environment varies according to the configuration of the parameters of the LoRa signal. The vast majority of WSN studies near the ground show results in scenarios somewhat different from those found inside an archaeological park. [4] Therefore, a model suitable for this environment will be of great importance to ensure the deployment and operation of a communication system, as developed in [5], the localization by obtaining RSSI data from a network of sensors close to the ground over an area of an agricultural farm at the frequency of 868 $\mathrm{MHz}$, with antenna heights of $40 \mathrm{~cm}$ above the ground, and in [6]develops localization using RSSI with applications of LoRa technology at $868 \mathrm{MHz}$ frequency through three localization algorithms, based on the simplified equation of the log distance model, but this time distance is the unknown variable, 100 RSSI samples are obtained throughout the indoor and outdoor scenarios, obtaining the a and $n$ that characterize the canal of propagation of the LoRa signal. The research is organized as follows. Section II describes the archaeological park scenarios in more detail. Section III describes the equipment used and the methodology for obtaining the experimental data. Section IV presents the results obtained and the analysis of these results for each scenario, obtaining a model for each one of them. Finally, section V contains the conclusions.

\section{NEAR GROUND SCENARIOS}

Most studies were conducted for WSN applications with antenna height just above ground level, although a few consider the variation of this, but not uncommon scenarios such as archaeological parks. These scenarios close to the ground are usually very complex because they experience the reflection, obstruction, and absorption of the signal, produced in the soil, vegetation, and other scatterers present in the environment. As is the case in [7], measurements are performed in three different outdoor environments, at $2.4 \mathrm{GHz}$ frequency, varying the antenna height, as well as the separation distance between them up to $100 \mathrm{~m}$, along a straight line. On the other hand, in 


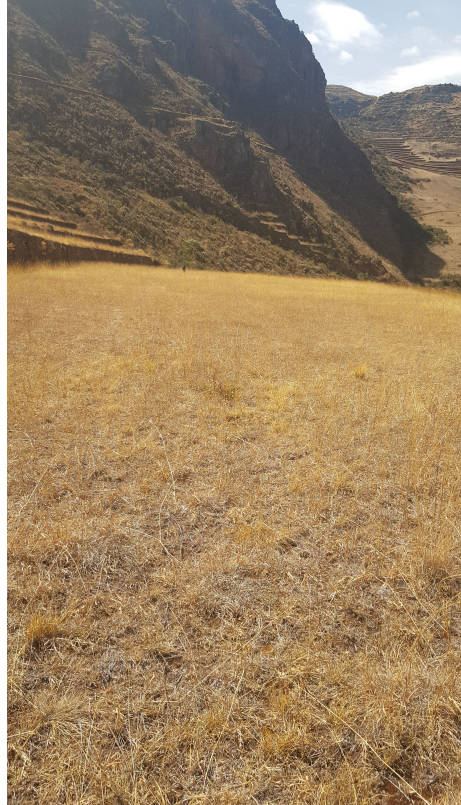

(a) Line of Sight

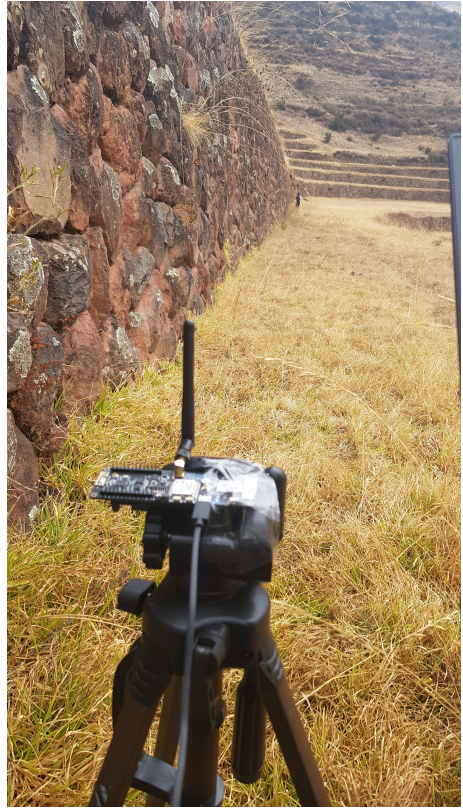

(b) Inca Wall

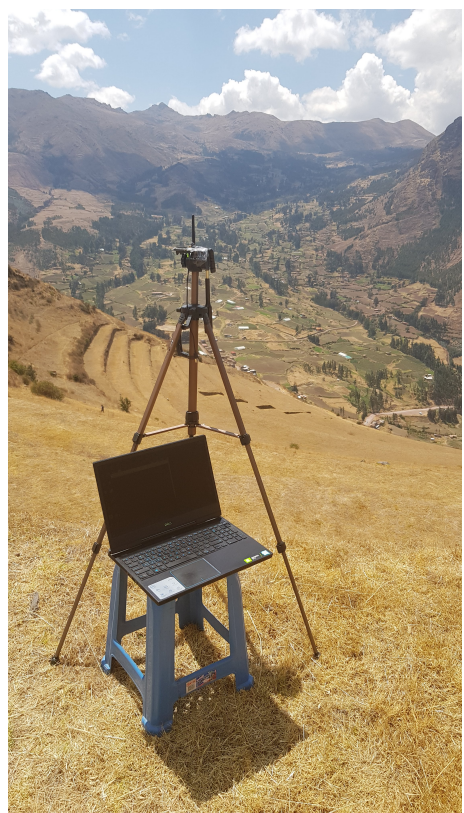

(c) Platforms

Fig. 1. Measurements Sites.

[8] an attempt is made to observe the influence of the antenna height against the important parameters within the modeling of the wireless propagation channel, obtaining values for each antenna height of the propagation loss exponent, shadowing factor, fading and propagation delay. For [9], measurements were made in the botanical park of the Florida institute of technology, at $1925 \mathrm{MHz}$ with antenna height $20 \mathrm{~cm}$ above the ground, obtaining the RSS value at variable distances of $5 \mathrm{~m}$ meters difference, in turn at radial angles separated by 22.5 degrees along 128 measurement points with 300 samples for each one. [10] describes the NWB measurements in an agricultural field with 3 different types of terrain with directional antennas and identical omnidirectional antennas, with working frequencies of 868,2400 , and $5800 \mathrm{MHz}$, the measurements are developed at 20 and $40 \mathrm{~cm}$ above the ground, the received power data is obtained for each antenna and in turn for each antenna height, thus developing a model of 3 slopes, with 3 different values of propagation loss exponent. Similarly, for [11], measurements are made in an indoor scenario with antenna heights close to the ground at the $2.45 \mathrm{GHz}$ frequency, showing how the propagation exponent varies with respect to the scatterers present in this indoor scenario.

Therefore, the correct modeling of the wireless propagation channel will be of utmost importance for the design and correct deployment of a wireless sensor network inside the archaeological park of Pisac, a clear example being [12], where the RSSI of a LoRa system is used to estimate the position in an indoor environment. In this work three different scenarios were selected, they are a large plain with a wide line of sight, the Inca walls, and the famous platform systems. The archeological park of Pisac is located in the district of the same name in the province of Calca in the department of Cusco, 32 $\mathrm{km}$ northwest of Cusco. It has an area of 9,063 hectares and a perimeter of 43,340 meters. The first scenario is located in the qosqa sector where there is a flat area with a wide line of sight, with a width of $15 \mathrm{~m}$ and a length of $153 \mathrm{~m}$, the ground is covered with grass $4 \mathrm{~cm}$ high, and the morphology is slightly undulating. Fig. 1a. The second scenario is the Inca walls, Fig. 1b, which are constructions made for containment purposes built with pebble stones. It has a cellular rig and convex profiles, masoned with clay mortar or mud, so they offer sufficient strength to remain largely intact until today. It has a variable height of 3 to 7 meters, with lengths of approximately $150 \mathrm{~m}[13]$.

And finally, the terrace scenario found between the q'alla q'asa and q'antus raq'ay sector, like most of the terraces within this archaeological park, has a circular shape, as shown in Fig. 1c, have sizes from 3 to 8 meters, with lengths of approximately 190 meters. Within this scenario, the transmitting and receiving antennas were obstructed by some platforms, so it should be noted that some experimental data are given without line of sight.

\section{Material AND Methods}

\section{A. Hardware Setup}

The experimental data collection was based on two TTGO T-Beam wireless nodes, one configured as a transmitter and the other as a receiver, the latter connected to a laptop to store the raw data (the value of the RSS (Received Signal Strength) variation is stored). The communication between the receiver node and the laptop is made use of the Arduino IDE development environment, and also makes use of Teraterm software for the conversion of data to an Excel workbook in .xlsx format for processing in Matlab. Some characteristics of the TTGO equipment are mentioned in Table I.

TTGO T-Beam nodes work in the unlicensed bands' ISM (Industrial, Scientific, and Medical), for this work we used the 
band of $920 \mathrm{MHz}$ since the $915 \mathrm{MHz}$ band is licensed to the telecommunications company Viettel Peru S. A.C. in the 902$915 \mathrm{MHz}$ frequencies, and according to the MTC [14] also the radio-communications services that operate in these bands must accept the harmful interference resulting from these applications and in no case will cause interference in the ISM applications. A pair of vertically polarized omnidirectional antennas with a gain of $3 \mathrm{dBi}$ is used, both antennas are connected to the transmitter and receiver via their SMA port, the transmitter emits a signal of $+20 \mathrm{dBm}$. More information on TTGO T-Beam can be found at [15].

TABLE I. LoRA Signal PARAmeters [15]

\begin{tabular}{|c|c|}
\hline PARAMETERS & SETTINGS \\
\hline Transceiver Chip & Semtech LoRa SX1276 \\
\hline Bandwidth & $500 \mathrm{KHz}$ \\
\hline Center Frequency & $920 \mathrm{MHz}$ \\
\hline Power Transmission & $+20 \mathrm{dBm}$ \\
\hline Transmission Speed & $5470 \mathrm{bps}$ \\
\hline Spreading Factor & 8 \\
\hline
\end{tabular}

\section{B. Measurement Methodology}

The same methodology was used for the LOS and Inca walls scenarios. The receiver was fixed at variable heights of $20,50,80$, and $120 \mathrm{~cm}$, and the transmitter at $150 \mathrm{~cm}$, the height of the receiving antenna was fixed at these heights, since we did not want to disharmonize the archaeological park, in addition to the existence of location signals with these sizes.

For the LOS scenario, the transmitter made a round trip in a straight line, with a total distance of $150 \mathrm{~m}$ at a constant speed of $0.4 \mathrm{~m} / \mathrm{s}$, this to characterize the fading experienced by the propagation signal within this environment, about 4050 data were obtained per trip, it should be noted that within this first scenario no people were found so the variations are due to the movement of the transmitter and the geomorphology of the terrain. The measurements were made in a cold-dry climate with light wind currents.

For the scenario of Inca walls, the same methodology was used to obtain the experimental data, the receiving antenna was placed at a distance of $1 \mathrm{~m}$ from the wall and then make straight stretches with the transmitter back and forth at the same constant speed of $0.4 \mathrm{~m} / \mathrm{s}$, the same variations in height of the receiver, until reaching the end of the wall, with a distance of $128 \mathrm{~m}$. A total of 2550 data were obtained. The measurements were performed with the same weather and light wind currents.

For our last scenario of Inca terraces, the methodology was changed since it is not possible to perform mobile measurements since these can reach heights of up to $8 \mathrm{~m}$. Therefore, it was decided to take experimental data for each platform, obtaining 500 samples for each one of them, for a total of 13 platforms. The measurements were carried out in the same climate and with light wind currents.

\section{Measurement Results and Analysis}

For this research, the following distribution of tasks is taken into account for the correct analysis of measurement data. See Fig. 2.

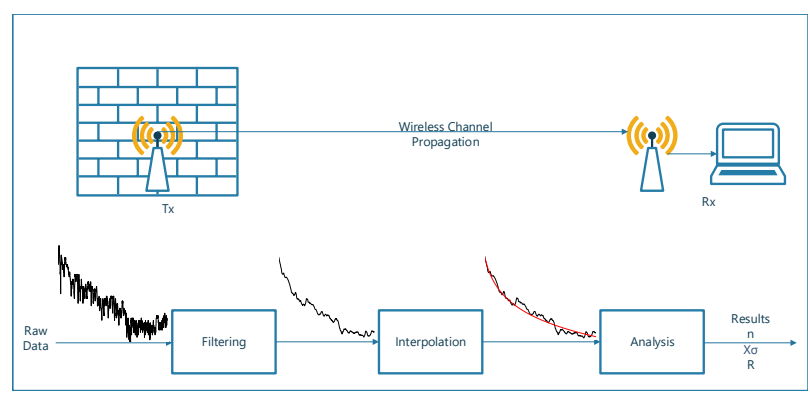

Fig. 2. Block Diagram of Measurements and Analysis of Data.

\section{A. Extraction of Loss Propagation Exponent and Shadowing Fading}

Once the experimental data were obtained, signal filtering was performed. The RSS data is passed through the moving average filter with a window length of $40 \lambda$ [16] to separate the small-scale fading, see Fig. 3a-3b thus obtaining the largescale fading, where the linear regression algorithm is applied in Matlab using the method of least squares and app curve Fitting, to obtain the signal parameters such as the exponent of the propagation loss, the reference power, and the standard deviation or shadowing.

With the data obtained after filtering, they resemble the logarithmic distance propagation loss model, where the propagation loss exponent indicates the change in propagation loss as a function of distance. The values of the exponent and shadow fading are extracted from the following equation 1 [17]:

$$
\operatorname{Pr}(d)=\operatorname{Pr}_{o}+10 n \log _{10}(d)+X_{\sigma}[d B]
$$

Where $d$ is the variation distance between $\mathrm{Tx}$ and $\mathrm{Rx}$ in meters, $\operatorname{Pr}(d)$ is the received power in $\mathrm{dBm}$, and $X_{\sigma}$ is a zeromean log-normal random variable with standard deviation $\sigma$ in $\mathrm{dB}$, which expresses the shadow fading. Linear regression is used to obtain the propagation loss exponent $n$. The two-slope model is adopted to fit the experimental data on the Inca walls, using the equation 2 [18].

$$
\operatorname{Pr}(d)=\left\{\begin{array}{l}
\operatorname{Pr}\left(d_{0}\right)+10 n_{1} \log _{10}\left(\frac{d}{d_{0}}\right)+X_{\sigma_{1}}\left(d \leq d_{b}\right) \\
\operatorname{Pr}\left(d_{b}\right)+10 n_{2} \log _{10}\left(\frac{d}{d_{b}}\right)+X_{\sigma_{2}}\left(d>d_{b}\right)
\end{array}\right.
$$

Small-scale signal variation is characterized by the Rician, Nakagami-m and Rayleigh distribution equations, these equations of these distributions are found in [19].

\section{B. Modeling and Analysis}

The variation of the measurements with respect to the height of the Rx antenna, after filtering as observed in Fig. 3c. Once the large-scale fading signal is obtained, the linear regression algorithm is used to obtain the values of the propagation loss exponent and the shading factor of this archaeological park. Using MATLAB software, the resulting equation was obtained, based on the equation 1, this model will be validated using two parameters, the residual standard deviation $(\sigma)$ and the coefficient of determination $\left(R^{2}\right)$. These parameters are shown in the Table II and Table III, for the one slope model and 


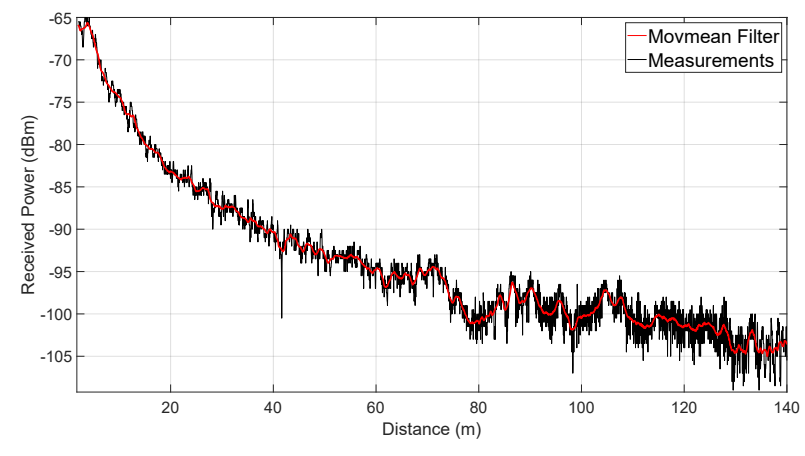

(a)

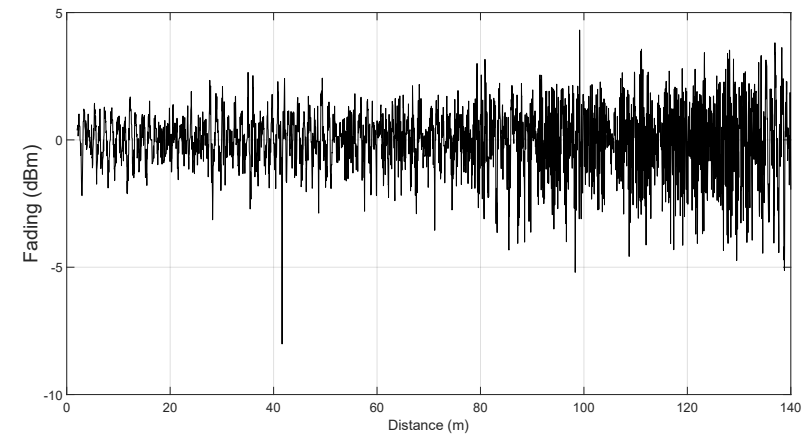

(b)

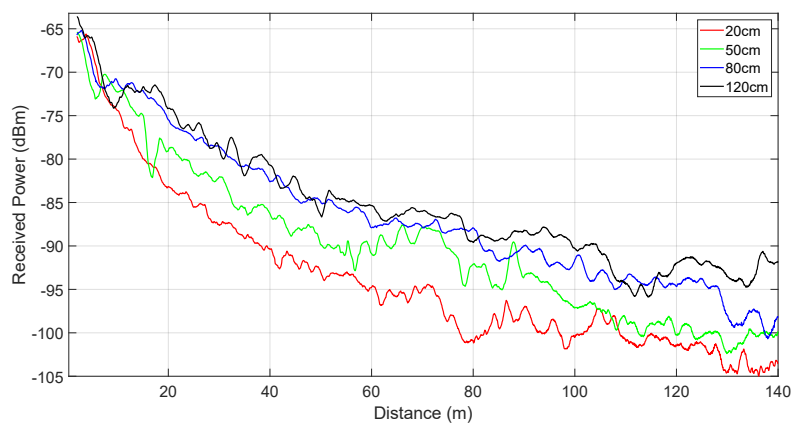

(c)

Fig. 3. Signal Filtering, (a) Measurements vs Moving Average Filter, (b) Small-Scale Signal, (c)Large-Scale Signal.

two slope model, respectively. The residual standard deviation measures the average deviation of the measured propagation losses from the values predicted by the fit model. If the value of $\sigma$ is close to 0 , it indicates a better fit. The coefficient of determination expresses the degree of success of the fit. If $R^{2}$ is close to 1 it means that the fit is optimal, the leastsquares line fits the obtained data [20]. See Fig. 4a, 4b, 4c. It should be noted that our results are comparable to existing values in litetarua [8], [21], however, new values and aspects of antenna height and particular archaeological park scenarios are provided that are in accordance with intuition. The dependence on the height of the receiving antenna as well as the nature of the scenario is demonstrated since its value decreases as the height increases, the exponent values range between 1.9-2.4 for the LOS scenario, 2.1-2.7 for the wall scenario, and finally 1.3-1.4 on the platforms, the latter since the resulting height is the sum of the platform height and the antenna height. The shadowing variation is not strongly impacted by the height of the receiving antenna, the statistical distribution of shadowing is confirmed to have a normal distribution, with deviations ranging from 1.7-2 for the LOS scenario, 1.7-2.3 for walls, and 7.7-8.4 for platforms.

For the analysis of the fading, the Normal distribution models were used for shadowing fading, and for small-scale fading, Rice, Nakagami-m, and Rayleigh, each of which was simulated and contrasted with the measurements. As can be seen in the Fig. 5a, 5b. For the Shadowing data, it is again shown to have a normal distribution with mean zero and standard deviation calculated according to the scenario. For the small-scale data, both the Rice and Nakagami-m distributions are appropriate for this archaeological park scenario.

\section{CONClusion}

In order to characterize the archaeological park of Pisac, we performed measurements at $920 \mathrm{MHz}$, obtaining the RSS value at different heights of $\mathrm{Rx}$ antenna, close to the ground so as not to affect the structural harmony of the same. The moving average filter is used to mitigate the small-scale fading, with a window of 40 , obtaining the large-scale fading where we establish statistical models of propagation loss and also analyze the influence of the height of the receiving antenna and the geomorphology of the terrain. The linear regression for the experimental data indicates that the model based on the logarithmic distance performs an adequate characterization for scenarios close to the ground within this archaeological park since the values found are close to 2 , the value of propagation loss exponent in free space, in addition to having adequate values for the determination coefficient $R^{2}$ and $R M S E$ or $X_{\sigma}$, on the other hand, it is observed that the dual-slope model shows greater accuracy in these scenarios, obtaining values of $R^{2}$ higher than the single-slope model. The smallscale signal fading statistics can be modeled as a nakagami-m distribution and a rice distribution, which show a considerable approximation with our samples. Additionally, the obtained model was compared with experimental data from another archaeological park, Chinchero, see Fig. 6, obtaining a value of $R^{2}$ equal to 0.9291 , which indicates that the model fits the 


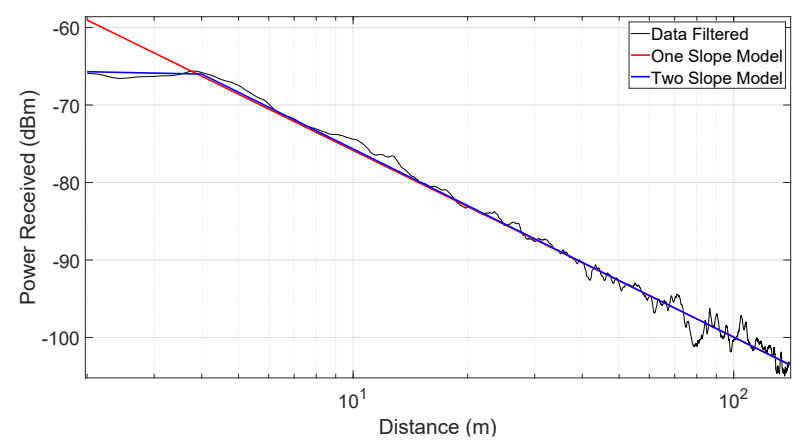

(a)

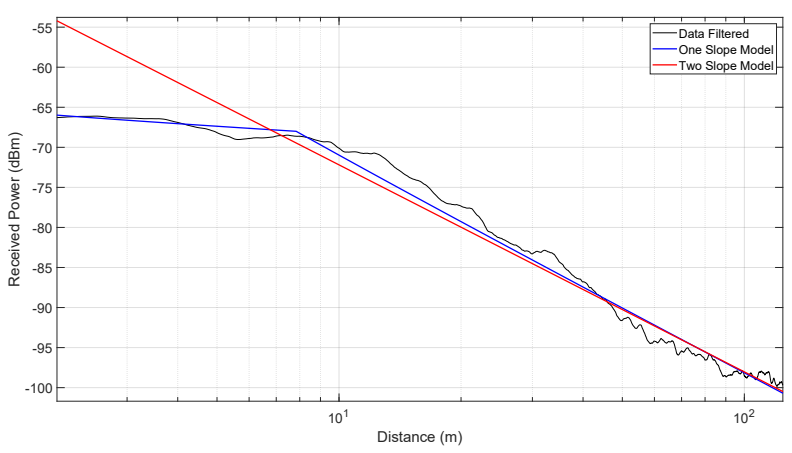

(b)

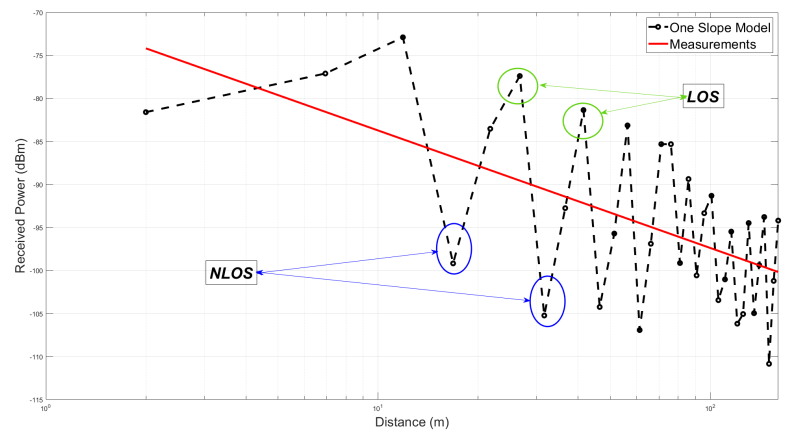

(c)

Fig. 4. Large-Scale Signal Modeling,

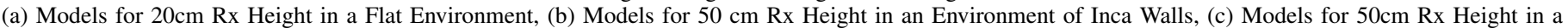
Platform Environment

TABle iI. Large Scale Fading Characteristics for loS, InCa Walls and Platforms- One SLope Model

\begin{tabular}{cccccccccc}
\hline \multicolumn{10}{c}{ One Slope Model } \\
\hline \multicolumn{19}{c}{ Line of Sight } & \multicolumn{9}{c}{ Inca Walls } & Platforms \\
\hline $\begin{array}{l}\text { Height } \\
(\mathrm{cm})\end{array}$ & $\mathrm{n}$ & $\begin{array}{l}X_{\sigma} \\
(\mathrm{dB})\end{array}$ & $\begin{array}{l}R^{2} \\
(\%)\end{array}$ & $\mathrm{n}$ & $\begin{array}{l}X_{\sigma} \\
(\mathrm{dB})\end{array}$ & $\begin{array}{l}R^{2} \\
(\%)\end{array}$ & $\mathrm{n}$ & $\begin{array}{l}X_{\sigma} \\
(\mathrm{dB})\end{array}$ & $\begin{array}{l}R^{2} \\
(\%)\end{array}$ \\
\hline 20 & 2.408 & 1.196 & 0.9825 & 2.774 & 2.113 & 0.9610 & 1.285 & 8.342 & 0.3135 \\
\hline 50 & 2.249 & 2.082 & 0.9419 & 2.514 & 2.0 & 0.9575 & 1.444 & 7.732 & 0.4017 \\
\hline 80 & 2.142 & 1.958 & 0.9433 & 2.407 & 2.343 & 0.9377 & 1.362 & 8.401 & 0.3359 \\
\hline 120 & 1.949 & 1.754 & 0.9449 & 2.102 & 1.719 & 0.9553 & 1.366 & 8.065 & 0.3556 \\
\hline
\end{tabular}

experimental data optimally, validating our model in another archaeological park scenario with similar morphology of the environment. A report on the measurement campaign of the propagation channel by means of mobile measurements with variable antenna height is provided, proving once again the dependence of the propagation signal with the separation distance between $\mathrm{Tx}$ and $\mathrm{Rx}$, so that new values of propagation exponent, shadowing factor and small-scale signal distributions were also provided, for archaeological park scenarios, which vary in morphology to those developed in other investigations. Finally, it is concluded that, for the correct study and analysis of the deployment and operation of a sensor network, an adequate propagation model with parameters adjusted to the different scenarios within the archaeological parks must be taken into account. These models could be used as tools for the implementation of object localization based on the trilateration algorithm using RSSI. In addition to obtaining the path loss equation that will provide the coverage area.

\section{ACKNOWLEDGMENT}

The authors acknowledge funding support from CONCYTEC-PROCIENCIA and The World Bank within the call E041-2018 [contract number 128-2018-FONDECYT-BMIADT-SE].

\section{REFERENCES}

[1] I. Mashal, O. Alsaryrah, T.-Y. Chung, C.-Z. Yang, W.-H. Kuo, and D. P. Agrawal, "Choices for interaction with things on internet and underlying issues," Ad Hoc Networks, vol. 28, pp. 68-90, 2015. 


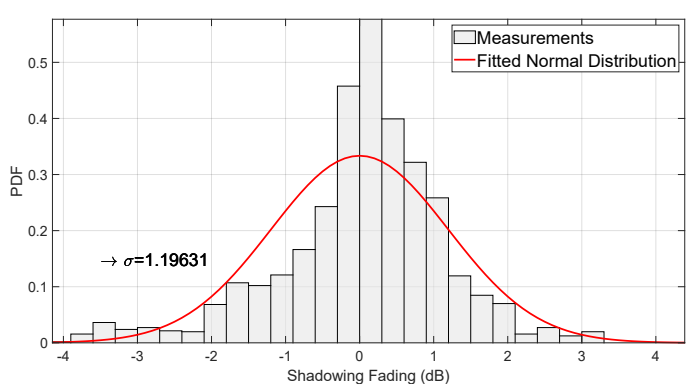

(a)

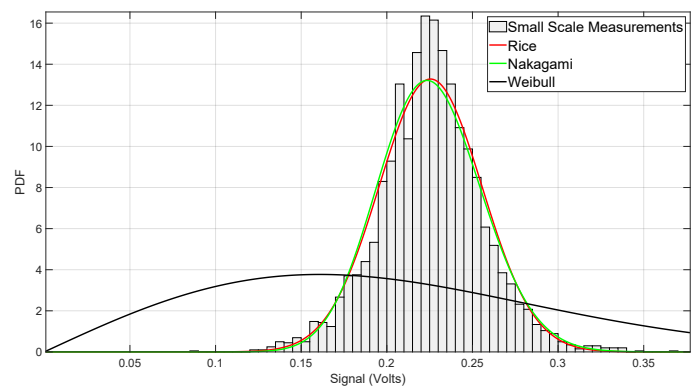

(b)

Fig. 5. Signal Fading Models,

(a) Model Shadowing Fading for $20 \mathrm{~cm}$ in an Environment of LOS, (b) Models for Small-Scale Fading for $80 \mathrm{~cm}$ in an Environment of Inca Walls.

TABLE III. LARge ScAle FAding Characteristics for LOS, InCA WALlS AND PlatForms- Two SLOPE Model

\begin{tabular}{ccccccccc}
\hline \multicolumn{10}{c}{ Two Slope Model } \\
\hline \multicolumn{10}{c}{ Line of Sight } \\
\hline $\begin{array}{l}\text { Height } \\
(\mathrm{cm})\end{array}$ & $\mathrm{n} 1$ & $\mathrm{n} 2$ & $\begin{array}{l}X_{\sigma} \\
(\mathrm{dB})\end{array}$ & $\begin{array}{l}R^{2} \\
(\%)\end{array}$ & $\mathrm{n} 1$ & $\mathrm{n} 2$ & $\begin{array}{l}X_{\sigma} \\
(\mathrm{dB})\end{array}$ & $\begin{array}{l}R^{2} \\
(\%)\end{array}$ \\
\hline 20 & 0.1 & 2.43 & 1.0975 & 0.9857 & 0.1 & 3.17 & 1.5691 & 0.9784 \\
\hline 50 & 0.7 & 2.28 & 1.8589 & 0.9537 & 0.3 & 2.67 & 1.2441 & 0.9836 \\
\hline 80 & 0.8 & 2.14 & 1.6362 & 0.9604 & 0.6 & 2.52 & 1.6741 & 0.9682 \\
\hline 120 & 1 & 2.07 & 1.4847 & 0.9605 & 0.9 & 2.17 & 1.4439 & 0.9684 \\
\hline
\end{tabular}
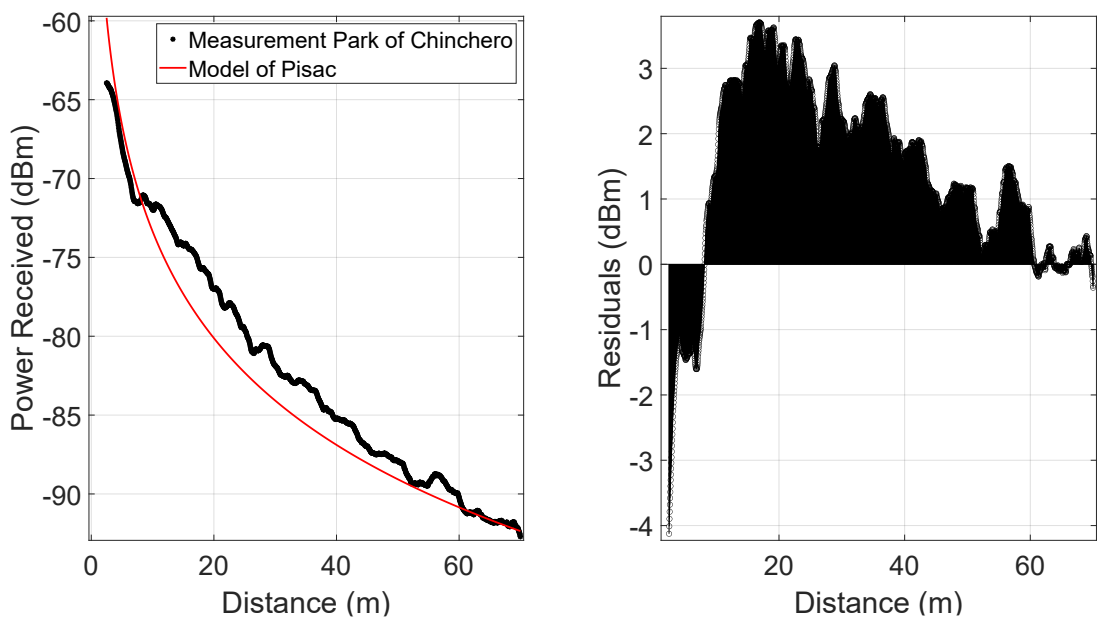

Fig. 6. Model of Pisac Vs Measurement in Park Archaeological of Chinchero.

[2] J. Karedal, S. Wyne, P. Almers, F. Tufvesson, and A. F. Molisch, "A measurement-based statistical model for industrial ultra-wideband channels," IEEE transactions on wireless communications, vol. 6, no. 8, pp. 3028-3037, 2007.

[3] K. A. Ahmad, M. S. Salleh, J. D. Segaran, and F. R. Hashim, "Impact of foliage on lora $433 \mathrm{mhz}$ propagation in tropical environment," in AIP Conference Proceedings, vol. 1930, no. 1. AIP Publishing LLC, 2018, p. 020009.

[4] W. Tang, X. Ma, J. Wei, and Z. Wang, "Measurement and analysis of near-ground propagation models under different terrains for wireless sensor networks," Sensors, vol. 19, no. 8, p. 1901, 2019.

[5] W. T. EL-Gzzar, H. B. Nafea, and F. W. Zaki, "Application of wireless sensor networks localization in near ground radio propagation channel," in 2020 37th National Radio Science Conference (NRSC). IEEE, 2020, pp. $145-154$

[6] E. Goldoni, L. Prando, A. Vizziello, P. Savazzi, and P. Gamba, "Experimental data set analysis of rssi-based indoor and outdoor localization in lora networks," Internet Technology Letters, vol. 2, no. 1, p. e75, 2019.

[7] D. Wang, L. Song, X. Kong, and Z. Zhang, "Near-ground path loss measurements and modeling for wireless sensor networks at $2.4 \mathrm{ghz}$," International Journal of Distributed Sensor Networks, vol. 8, no. 8, p. 969712, 2012.

[8] S. Sangodoyin, S. Niranjayan, and A. F. Molisch, "A measurementbased model for outdoor near-ground ultrawideband channels," IEEE Transactions on Antennas and Propagation, vol. 64, no. 2, pp. 740751, 2015.

[9] A. Alsayyari, I. Kostanic, C. E. Otero, and A. Aldosary, "An empirical 
path loss model for wireless sensor network deployment in a dense tree environment," in 2017 IEEE Sensors Applications Symposium (SAS). IEEE, 2017, pp. 1-6.

[10] H. Klaina, A. Vazquez Alejos, O. Aghzout, and F. Falcone, "Narrowband characterization of near-ground radio channel for wireless sensors networks at 5g-iot bands," Sensors, vol. 18, no. 8, p. 2428, 2018.

[11] M. Salim, K. Sayidmarie, and A. Aboud, "Investigation of indoor propagation of wlan signals," Indonesian Journal of Electrical Engineering and Computer Science, vol. 16, no. 3, pp. 1356-1363, 2019.

[12] S. Kavetha and et al, "Indoor positioning utilizing bluetooth low energy rssi on lora system," Indonesian Journal of Electrical Engineering and Computer Science, vol. 23, no. 2, pp. 927-937, 2021.

[13] A. Chalco Salas, "Andenerías prehispánicas y gestión de riesgos. análisis de su puesta en valor como factor de desarrollo cultural, pisaccusco," 2017.

[14] M. de Transportes y Telecomunicaciones MTC, "Registro nacional de frecuencias- bandas de 899 - $915 \mathrm{mhz}$ y 944 - 960 mhz.pdf[online]," https://www.gob.pe/institucion/mtc/ informes-publicaciones/343585-registro-nacional-de-frecuencias, 2019.

[15] K. Gabriel, “Ttgo-t-beam-car-tracker," https://github.com/kizniche/ ttgo-tbeam-ttn-tracker, 2019.

[16] A. F. Molisch, Wireless communications. John Wiley \& Sons, 2012, vol. 34.

[17] A. Goldsmith, Wireless communications. Cambridge university press, 2005.

[18] T. S. Rappaport et al., Wireless communications: principles and practice. prentice hall PTR New Jersey, 1996, vol. 2.

[19] S. R. Saunders and A. Aragón-Zavala, Antennas and propagation for wireless communication systems. John Wiley \& Sons, 2007.

[20] L. R. Ojeda, "Probabilidad y estadística básica para ingenieros," Ecuador: Escuela superior politécnica del litoral, 2007.

[21] J. Molina-Garcia-Pardo and et al, "Channel model at $868 \mathrm{mhz}$ for wireless sensor networks in outdoor scenarios," in Proc. International Workshop on Wireless Ad-Hoc Networks (IWWAN 2005), 2005, pp. 2-5. 